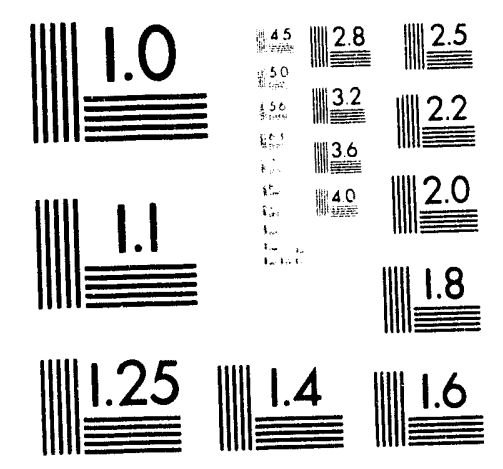



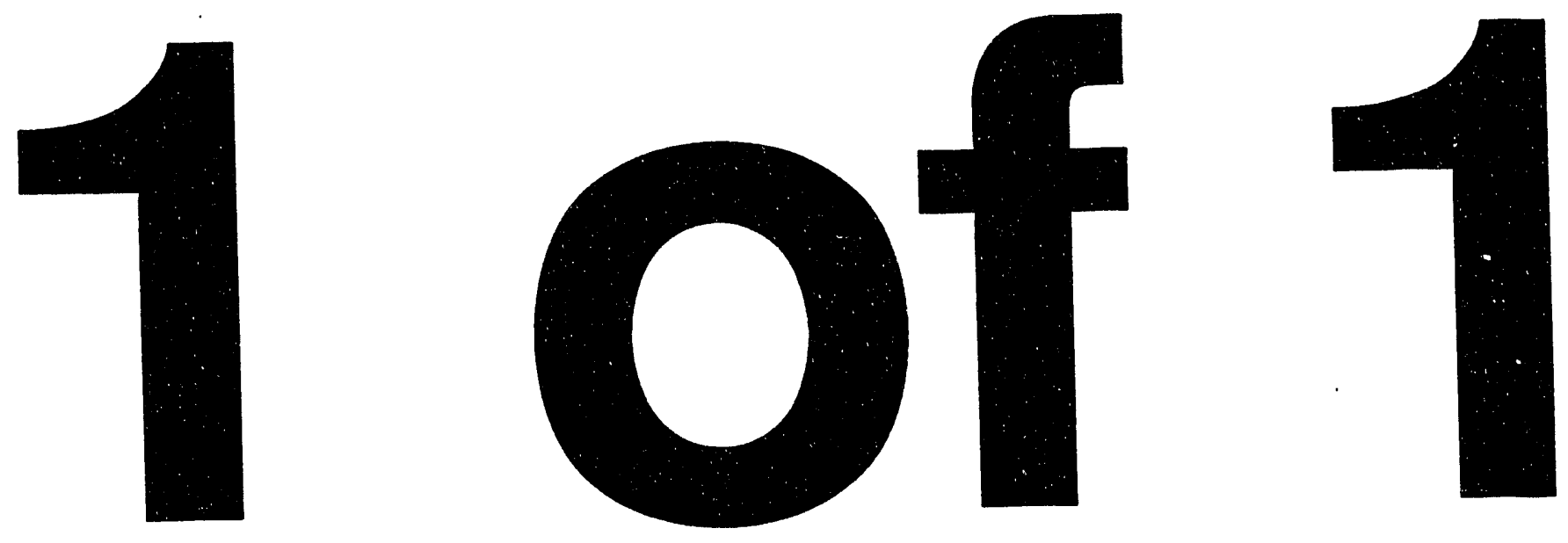

$=$ 


\title{
High Oxygen Pressure Synthesis of New Copper Oxide Superconductors*
}

\author{
B. Dabrowski, V. Zhang-MacCoy, Z. Wang, R. Hannon
}

Department of Physics

Northern Illinois University, DeKalb, IL 60115

J.D. Jorgensen, B.A. Hunter, D.G. Hinks, J.L. Wagner, and R.L. Hitterman

Science and Technology Center for Superconductivity

Materials Science Division

Argonne National Laboratory, Argonne, IL 60439

The submitted manuscript has been authored by a
contractor of the U.S. Government under contract
No. W-31-109-ENG-38. Accordingly, the U.S.
Governmerit retains a nonexclusive, royalty-tree
license to publish or reproduce the published form
of this contribution, or allow others to do so, for U.S.
Government purposes.

\section{DISCLAIMER}

This report was prepared as an account of work sponsored by an agency of the United States Neither the United States Government nor any agency thereof, nor any of their Government. Neither the United States employees, makes any warranty, express or implied, or assumes any legal hability or tor or bility for the accuracy, completeness, or usefulness of any information, apparatus, product, or process disclosed, or represents that its use would not infringe privately owned rights. Re trade name, trademark, ence herein to any specific commercial product, process, or service by trade name, trademar, manufacturer, or otherwise does not necessarily constitute or imply its endorsement, The views mendation, or favoring by the United States Government or any agency thereof The of the and opinions of authors expressed herein do not

United States Government or any agency thereof.

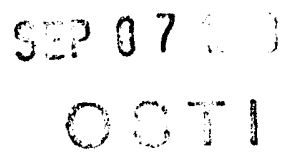

\footnotetext{
${ }^{*}$ Work supported by the National Science Foundation Division of Materials Research-Low Temperature Physics Program under grant \#DMR 87-19738 (BD, VZ, RH), the National Science Foundation Science and Technology Center for Superconductivity under contract \#DMR 91-2000 (ZW, BAH, JLW), and the U.S. Department of Energy, BES-Materials Sciences under contract \#W-31-109-ENG-38 (JDJ, DGH, RLH).
}

\section{Submitted: Physics and Chemistry of Molecular and Oxide Superconductors Conference, July 27-31, 1993, Eugene, OR}


High Oxygen Pressure Synthesis of New Copper Oxide Superconductors*

B. Dabrowski, V. Zhang-MacCoy, Z. Wang and R. Hannon, Department of Physics, Northern Illinois University, DeKalb, IL 60115

and

J.D. Jorgensen, B.A. Hunter, D.G. Hinks, J.L. Wagner and R.L. Hitterman, Materials Science Division, Argonne National Laboratory, Argonne, IL 60439

\section{ABSTRACT}

The unique coordination of the copper ions in $+1,+2$, and +3 oxidation states which are stable in a range of oxygen partial pressure, $10^{-6}<\mathrm{P}\left(\mathrm{O}_{2}\right)<10^{3}$ atm., makes possible the formation of a wide variety of distinct structures. By controlling the oxygen pressure during the synthesis and annealing, the distribution of metal- and oxygenions can be modified on an atomic scale to optimize the structural and electronic properties. We present several examples of compounds for which the critical structural elements for superconductivity, i.e. the perfectly ordered $\mathrm{CuO}_{2}$-planes, have been obtained and doped with holes by means of high oxygen pressure, $P\left(O_{2}\right)>1$ atm. These materials, $\mathrm{La}_{2} \mathrm{CuO}_{4+\delta}, \mathrm{La}_{2-x} \mathrm{Ca}_{x} \mathrm{CuO}_{4}$ and $\mathrm{YSr}_{2-x} \mathrm{La}_{x} \mathrm{Cu}_{3} \mathrm{O}_{7+\delta}$ offer a unique opportunity to study the relationship between superconductivity and structural, magnetic and chemical properties.

"This work is supported by the National Science Foundation, Division of Materials Research - Low Temperature Physics Program under grant \#DMR 87-19738 (BD, VZ, RH) and the National Science Foundation Science and Technology Center for Superconductivity under grant \#STC 91-20000 (ZW, BAH, JLW) and the U.S. Department of Energy, Division of Basic Energy Sciences - Materials Sciences under contract No. W-31-109-ENG-38 (JDJ, DGH, RLH). 
1. INTHODUCITON

Copper oxide compounds are usually prepared in air or under reducing conditions, $\mathrm{P}\left(\mathrm{O}_{2}\right)<1$ atm., but there are several examples where the superconducting composition can be prepared only under high oxygen pressure, $\mathrm{P}\left(\mathrm{O}_{2}\right)>1 \mathrm{~atm} .^{1} \mathrm{We}$ have used high oxygen pressure in several ways to obtain polycrystallirie and singlecrystal compounds with perfectly ordered $\mathrm{CuO}_{2}$-planes and dope the planes with holes to achieve superconductivity. Annealings at low temperatures, below $600^{\circ} \mathrm{C}$, were necessary to increase the oxygen content of the antiferromagnetic semiconductor, $\mathrm{La}_{2} \mathrm{CuO}_{4}$, to convert it to a metallic superconductor. ${ }^{2}$ Synthesis at high temperatures, $\sim 1100{ }^{\circ} \mathrm{C}$, was used to extend the calcium solid-solubility limit in $\mathrm{La}_{2-x} \mathrm{Ca}_{x} \mathrm{CuO}_{4}$ to $x=0.2$, allowing for the first time an observation of "overdoped" compositions, similar to the Sr-substituted material. ${ }^{3}$ Substitution of lanthanum for strontium and the synthesis at high temperatures was necessary to prepare a new structural analog of $\mathrm{YBa}_{2} \mathrm{Cu}_{3} \mathrm{O}_{7}$, the $\mathrm{Sr}$-based superconductor $\mathrm{YSr}_{1.6} \mathrm{La}_{0.4} \mathrm{Cu}_{3} \mathrm{O}_{7.2}$ with $T_{C} \sim 60 \mathrm{~K} .{ }^{4}$ Here, we will discuss how high oxygen pressure synthesis and annealing can be used to achieve desired structural and electronic properties of these important materials.

\section{EXPERIMENTAL}

Polycrystalline samples of complex copper oxides were synthesized from stoichiometric mixtures of oxides and / or carbonates using the standard ceramic route. Samples were fired in air at $920-980{ }^{\circ} \mathrm{C}$ for 48 hours with frequent intermediate grindings. High pressure annealings at $400-940^{\circ} \mathrm{C}$ under $200-300$ bar of pure oxygen were done using an externally heated reaction vessel made of high strength Rent '41 alloy. Annealings were done using long equilibration times, 24-48 hours, and very slow cooling rates, 0.1-1.0 deg/min. for maximum oxygen uptake. High pressure synthesis was done in an internally heated HIP system for 12 hours in $20 \% \mathrm{O}_{2} /$ argon at a total pressure of $3000 \mathrm{~atm}$. (600 atm. $\mathrm{O}_{2}$ pressure) at $1100-1180^{\circ} \mathrm{C}$, followed by slow cooling ( $1.5 \mathrm{deg} / \mathrm{min}$.) to room temperature.

Sample homogeneity was checked by powder $x$-ray diffraction. Neutron powder diffraction data were obtained using the Special Environment Powder Diffractometer at Argonne's Intense Pulsed Neutron Source. Susceptibility measurements were 
performed with a Lake Shore Cryotronics a.c. susceptometer in a 1 Gauss fieid. Resistivity was measured using a standard four-lead d.c. measurement. Oxygen content was determined from thermogravimetric analysis measurements using a Cahn TG171 system.

\section{RESULTS}

\subsection{Annealings at low temperature: $\mathrm{La}_{2} \mathrm{CuO}_{4+\delta}$}

In the pseudo-binary La - Cu - O system, three stable phases are known to form as a function of oxygen partial pressure. ${ }^{1}$ Around $900{ }^{\circ} \mathrm{C}$, at low pressures, $\log \left[\mathrm{P}\left(\mathrm{O}_{2}\right)\right]$ $<-5$, semiconducting $\mathrm{LaCu}^{+1} \mathrm{O}_{2}$ forms. In the intermediate pressure range, $-5<$ $\log \left[\mathrm{P}\left(\mathrm{O}_{2}\right)\right]<2$, the parent material of the first high temperature superconductor, $\mathrm{La}_{2} \mathrm{Cu}^{+2} \mathrm{O}_{4}$, is stable. For higher pressures, $\log \left[\mathrm{P}\left(\mathrm{O}_{2}\right)\right]>2$, the metallic but not superconducting, $\mathrm{LaCu}^{+3} \mathrm{O}_{3}$, can be synthesized.

We have shown that lanthanum copper oxide, $\mathrm{La}_{2} \mathrm{CuO}_{4+\delta}$, forms at the stoichiometric metal ion ratio and, thus, the structural and transport properties depend only on the oxygen stoichiometry that is determined by the annealing conditions. ${ }^{2}$ Our further studies revealed that $\mathrm{La}_{2} \mathrm{CuO}_{4+\delta}(\delta>0)$ at $10 \mathrm{~K}$ consists of two nearly identical orthorhombic phases: the nearly stoichiometric, $\mathrm{La}_{2} \mathrm{CuO}_{4}$, which is antiferromagnetic and the oxygen-rich, $\mathrm{La}_{2} \mathrm{CuO}_{4.08}$, phase which is superconducting. ${ }^{5}$ The abundance of the second phase increases as the oxygen pressure at which the samples are prepared is increased. This phase separation occurs reversibly below $320 \mathrm{~K}$. Above $320 \mathrm{~K}$, lanthanum copper oxide is a single phase material the overall oxygen stoichiometry determined by the oxygen pressure during annealing.

The temperature dependence of resistivity is very sensitive to the oxygen content for $\mathrm{La}_{2} \mathrm{CuO}_{4+\delta}$. The $25000 \mathrm{~atm}$. $\mathrm{O}_{2}$-annealed sample is metallic and superconducting with a sharp transition at $38 \mathrm{~K}$. The two-phase 1 and $100 \mathrm{~atm} . \mathrm{O}_{2}$-annealed samples display a broad resistive anomaly in the 180-300 $\mathrm{K}$ range and a sharp superconducting drop below $38 \mathrm{~K}$. The resistive anomaly is due to the phase separation process that occures in this temperature range and is present only for the two-phase samples.

We have constructed the approximate phase diagram for $\mathrm{La}_{2} \mathrm{CuO}_{4+\delta}$ using 
powder neutron diffraction, thermogravimetric analysis, resistivity and magnetization data. $^{2}$ The phase separation into nearly stoichiometric and oxygen-rich phases occurs near room temperature for $0<\delta<0.08$. Two phase samples in that composition range display mixed antiferromagnetic and superconducting behavior. The oxygen enters the lattice as an $\mathrm{O}^{-2}$ ion and is highly mobile at $180-300^{\circ} \mathrm{C}$. The oxygen stojchiometry of the superconducting phase is 4.08 and the excess oxygen dopes the system in the same way as $\mathrm{Sr}^{+2}$ or $\mathrm{Ca}^{+2}$ substitution for $\mathrm{La}^{+3}$. The complicated structural, magnetization and resistivity data can be consistently explained using our phase diagram.

\subsection{Extension of the solid-solubility region: $\mathrm{La}_{2-x} \mathrm{Ca}_{x} \mathrm{CuO}_{4}$}

The $\mathrm{La}_{2} \mathrm{CuO}_{4}$ based materials offer a unique opportunity to study the relation between structural and superconducting properties because of the simplicity of the structure. The extensively studied Sr-substituted $\mathrm{La}_{2-x} \mathrm{Sr}_{x} \mathrm{CuO}_{4}$ is the only copper oxide compound displaying the whole range of physical properties observed for high temperature superconductors ranging from an antiferromagnetic insulator, through a superconducting metal to a nonsuperconducting metal. ${ }^{6}$ Since the decrease of $T_{C}$ is not fully understood for $x>0.15$, it is important to investigate the relation between the suppression of superconductivity and structural or chemical effects in this "overdoped" composition regime.

The isostructural calcium substituted $\mathrm{La}_{2-x} \mathrm{Ca}_{x} \mathrm{CuO}_{4}$ compound provides an opportunity to independently control the superconducting and structural properties since the calcium ionic size is smaller than lanthanum in contrast to strontium which is slightly larger. The calcium substituted system has not been studied in much detail due to the limited $\mathrm{Ca}$ solubility that can be achieved in air, $x \leq 0.10$, and the low maximum superconducting transition temperature, $T_{C} \sim 22 \mathrm{~K}$, observed for these doping ievels. 7 We have used high oxygen pressure synthesis to extend the solubility limit to the expected optimum composition for superconductivity and beyond. ${ }^{3}$

Samples synthesized in $600 \mathrm{~atm}$. of $\mathrm{O}_{2}$ at $1110-1140^{\circ} \mathrm{C}$ with $\mathrm{x}=0.15$ and 0.20 are single-phase but the $x=0.25$ sample shows a small amount of the double-CuO ${ }_{2}^{-}$ layer, $\mathrm{La}_{2-y} \mathrm{Ca}_{1+y} \mathrm{Cu}_{2} \mathrm{O}_{6+\delta}$, impurity phase. Thus, the calcium solubility limit lies slightly above $10 \%(x=0.2)$ at our synthesis conditions and it is possible that this limit 
could be further extended if higher pressures are used. From the thermogravimetric measurements, the oxygen content of $4.00 \pm 0.01$ was found for the $x=0.15$ and 0.20 samples, i.e., they appear to be fully stoichiometric in oxygen content and the hole doping of the $\mathrm{CuO}_{2}$ planes is as straightforward as for the Sr-substituted material.

We have confirmed that the Ca-solubility limit is indeed a function of an oxygen partial pressure by performing an additional annealings in air after syntheșis at 600 atm. of $\mathrm{O}_{2}$. Figure 1 shows the $x$-ray diffraction patterns for $x=0.2$ samples synthesized in air at $980^{\circ} \mathrm{C}$ and at 600 atm. of $\mathrm{O}_{2}$ at $1110^{\circ} \mathrm{C}$ and annealed in air at $980^{\circ} \mathrm{C}$ for several periods of time after high pressure synthesis. The unindexed peaks around 33 and $47.5 \mathrm{deg}$ indicate the presence of an impurity $\mathrm{La}_{2-y} \mathrm{Ca}_{1+y} \mathrm{Cu}_{2} \mathrm{O}_{6}$ phase for material synthesized in air at $980^{\circ} \mathrm{C}$ and for samples annealled again under identical conditions. The intensity of the impurity peaks slowly increases with time reaching, after several days, values similar to those observed for the airsynthesized material.

Our structural and superconducting characterization of $x=0.15$ and 0.20 samples showed that the tetragonal to orthorhombic transition occurs at higher temperatures than for the Sr-substituted material and that the superconducting transition temperature is suppressed in the overdoped region, as is observed for the Sr-substituted material. 6 Thus, we were able to conclude that the tetragonal-toorthorhombic transition, observed in Sr-substituted material for compositions near the disappearance of superconductivity, $x \sim 0.20$, is not responsible for the suppression of $T_{C}$ The suppression of superconductivit it is an intrinsic "electronic" effect that is independent of structure. Further, we observe that the superconducting $T_{c}$ 's are sligitly lower and the orthorhombic distortion larger in the $\mathrm{Ca}$ - than in Sr-substituted materials at the same doping level. A probable explanation for the reduction of $T_{C}$ in the $\mathrm{Ca}$ substituted material is the imperfection of the square $\mathrm{Cu}-\mathrm{O}$ network as measured by the orthorhombic disiortion, i.e., the perfect square network (observed for the tetragonal structure) should show the highest $T_{C}$ at a fixed doping level. Thus, the observed optimum composition for superconductivity, $x_{o p t} \sim 0.15$, in La 2 ${ }_{x}(\mathrm{Sr}, \mathrm{Ca})_{x} \mathrm{CuO}_{4}$ is probably the result of the overall suppression of $T_{C}$ with chemica! doping at high $x$ and a decrease of $T_{C}$ due to the orthorhombic distortion at low $x$.

\subsection{Creation of a new superconductor: $\mathrm{CuSr}_{2-x} \mathrm{La}_{x} \mathrm{YCu}_{2} \mathrm{O}_{7}$}

The $\mathrm{Sr}$ - based analog of $\mathrm{YBa}_{2} \mathrm{Cu}_{3} \mathrm{O}_{7}\left(\mathrm{YSr}_{2} \mathrm{Cu}_{3} \mathrm{O}_{7}\right)$ can be prepared only at 
very high oxygen pressures $\left(\mathrm{P}\left(\mathrm{O}_{2}\right) \geq 20000\right.$ atm. $){ }^{8}$ This material belongs to the 1212 type containing a single metal - oxygen layer in the intermediate region separating the double $\mathrm{CuO}_{2}$ planes; i.e., the composition may be written as $\mathrm{CuSr}_{2} \mathrm{YCu}_{2} \mathrm{O}_{7}$, since the two different $\mathrm{Cu}$ sites are different. Isostructural compounds, $\mathrm{Cu}_{1-x} \mathrm{M}_{x} \mathrm{Sr}_{2} \mathrm{Y}_{1}$ ${ }_{y} \mathrm{Ca}_{y} \mathrm{Cu}_{2} \mathrm{O}_{7+\delta}(\mathrm{M}=\mathrm{Al}, \mathrm{Ga}, \mathrm{Fe}, \mathrm{Co}, \mathrm{Ti}, \mathrm{Ge}, \mathrm{V}, \mathrm{Cr}, \mathrm{Mo}, \mathrm{W}$ and $\mathrm{Re})$, can be stabilized at atmospheric pressure by the complete or partial substitution of small transition or posttransition metals for copper on the chain site. 9 Using a layered charge distribution model we have designed and synthesized at $\mathrm{P}\left(\mathrm{O}_{2}\right)=600 \mathrm{~atm}$. the isostructural, superconduc'ing material, $\mathrm{CuSr}_{2-x} \mathrm{La}_{x} \mathrm{YCu}_{2} \mathrm{O}_{7+\delta}$, without substitution on the chain copper site. ${ }^{4}$ The appropriate kind of dopant and its amount were estimated from the observation that the amount of copper ion substitution in the intermediate region required to stabilize the 1212 structure for $\mathrm{Cu}_{1-x} \mathrm{M}_{x} \mathrm{Sr}_{2} \mathrm{Y}_{1-y} \mathrm{Ca}_{y} \mathrm{Cu}_{2} \mathrm{O}_{7+\delta}$ materials decreases with increasing formal valence of the substituting ion. To stabilize the Srbased 1212 structure, an increased amount of positive charge was required to be inserted into the intermediate region. We chose to increase the charge in the intermediate region by substitution $\mathrm{La}^{+3}$ on the $\mathrm{Sr}^{+2}$.

Air synthesized samples are multiple-phase for all synthesis temperatures studied. Figure 2 shows $x$-ray powder diffraction patterns for $\mathrm{CuSr}_{1.6} \mathrm{La}_{0.4} \mathrm{YCu}_{2} \mathrm{O}_{7+\delta}$ samples synthesized at several oxygen pressures. Clearly, the formation of the 1212 phase requires high oxygen pressure and high temperature. Material with a total impurity amount of less than 3 percent, was obtained using an oxygen pressure of 600 atm. at $1180^{\circ} \mathrm{C}$. Once formed, the material is stable in 1 and 0.01 atm. of oxygen to $\sim 850{ }^{\circ} \mathrm{C}$. The properties of $\mathrm{CuSr}_{1.6} \mathrm{La}_{0.4} \mathrm{YCu}_{2} \mathrm{O}_{7+\delta}$ depend on its oxygen content. Material prepared at $600 \mathrm{~atm}$. and $1180^{\circ} \mathrm{C}(\delta \sim 0.2)$ is a bulk superconductor with the superconducting transition temperature, $T_{C} \sim 60 \mathrm{~K}$. This material gradually loses oxygen when heated in pure oxygen but the weight loss is fully recovered on cooling. Anneals at lower oxygen pressure of $0.01 \mathrm{~atm}$. removes 0.11 oxygen atoms and lowers $\mathrm{T}_{\mathrm{C}}$ to $35 \mathrm{~K}$.

Neutron powder diffraction data show the structure to be tetragonal with space group P4/mmm (the tetragonal 123 structure). The $\mathrm{La}$ and $\mathrm{Sr}$ share the 123 - structure "Ba" site but with somewhat different positions. The refined $\mathrm{z}$ values for $\mathrm{La}$ and $\mathrm{Sr}$ 
show that La is $0.27 \AA$ closer to the basal plane $(z=0)$ than $\mathrm{Sr}$. The Cu1 and O4 atoms show large displacements perpendicular to the $\mathrm{c}$ axis, while the $\mathrm{O} 1$ atoms show large displacements perpendicular to the $\mathrm{Cu} 1-\mathrm{O} 1$ bond with the largest displacement lying in the basal plane. This displacement pattern for the oxygen atoms is what one would expect for relaxation of $\mathrm{O} 1$ and $\mathrm{O} 4$ atoms towards the $\mathrm{La}^{\mathrm{3}}+$ dimers at $(0,0, \pm 0.163)$.

\section{CONCLUSION}

Using ideas similar to these presented above high oxygen pressure technique can be utilized for synthesis of new phases which are unstable in air. Additionaly, new compositions of the materials which have a limited stability range at atmospheric pressure, can be formed or grown as single crystals, for example $\mathrm{GaSr}_{2} \mathrm{Y}_{1}$ ${ }_{x} \mathrm{Ca}_{x} \mathrm{Cu}_{2} \mathrm{O}_{7}$ and $\mathrm{YBa}_{2} \mathrm{Cu}_{4} \mathrm{O}_{8}$, respectively. ${ }^{10,11}$

\section{REFERENCES}

1. Phase Diagrams For High $T_{C}$ Superconductors, Editors J. D. Whitler and R.S. Roth, published by The American Ceramic Society (Oct. 1991).

2. B. Dabrowski, D.G. Hinks, J.D. Jorgensen and D.R. Richards, Mat. Res. Soc. Symp. Proc. Vol. 156 (1989) 69.

3. B. Dabrowski, et al. (to be published).

4. B. Dabrowski, V. Zhang-McCoy, R. Hannon, B.A. Hunter, J.D. Jorgensen, J.L. Wagner and R.L. Hitterman, Physica C208 (1993) 183.

5. J.D. Jorgensen, B. Dabrowski, Shiyou Pei, D.G. Hinks, L. Soderholm, B. Morosin, L.E. Schiber, E.L. Venturini and D.S. Ginley, Phys. Rev. B 38 (1988).

6. J.B. Torrance, Y. Tokura, A.I. Nazzal, A. Bezinge, T.C. Huang and S.S.P. Parkin, Phys. Rev. Lett. 61 (1988) 1127.

7. M. Fukuoka, Y. Nakayama, Y. Tomioka, K. Kishio and K. Kitazawa, Physica C 190 (1991) 91.

8. B. Okai, Jap. J. Appl. Phys. 29 (1990) L2180.

9. T. Den and T. Kobayashi, Physica C 196 (1992) 141.

10. B. Dabrowski, P. Radaelli, D.G. Hinks, A.W. Mitchell, J.T. Vaughey, D.A. Groenke and K.R. Poeppelmeier, Physica C 193 (1992) 63.

11. B. Dabrowski, K. Zhang, J.J. Pluth, J.L. Wagner and D.G. Hinks, Physica C 202 (1992) 271. 


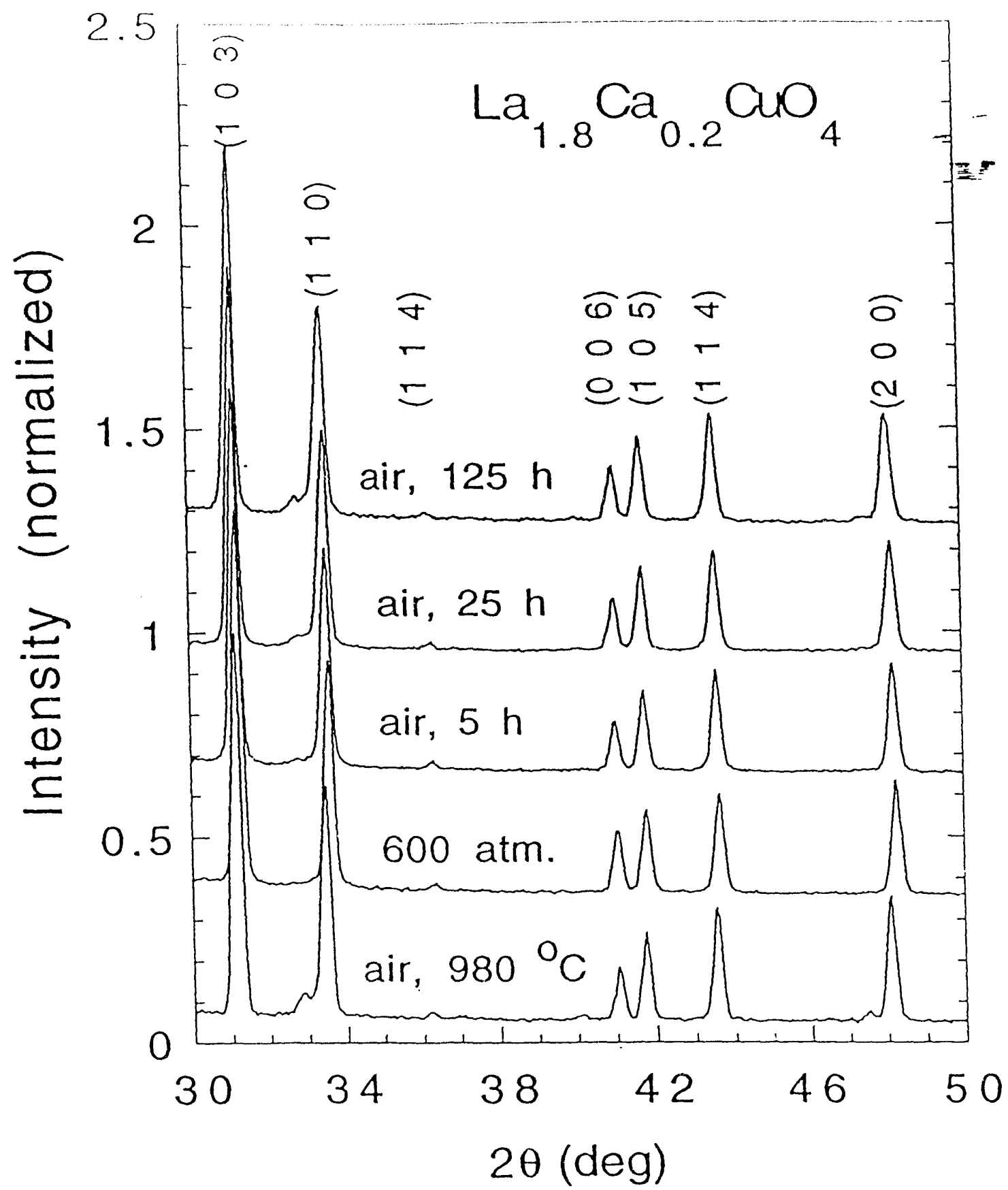

Fig. $1 \mathrm{X}$-ray powder diffraction patterns for $\mathrm{La}_{1.8} \mathrm{Ca}_{0.2} \mathrm{CuO}_{4}$ samples synthesized in air at $980{ }^{\circ} \mathrm{C}$ and at $600 \mathrm{~atm}$. of $\mathrm{O}_{2}$ at $1110^{\circ} \mathrm{C}$, and annealed in air at $980^{\circ} \mathrm{C}$ for 5,25 and 125 hours after high pressure synthesis. 


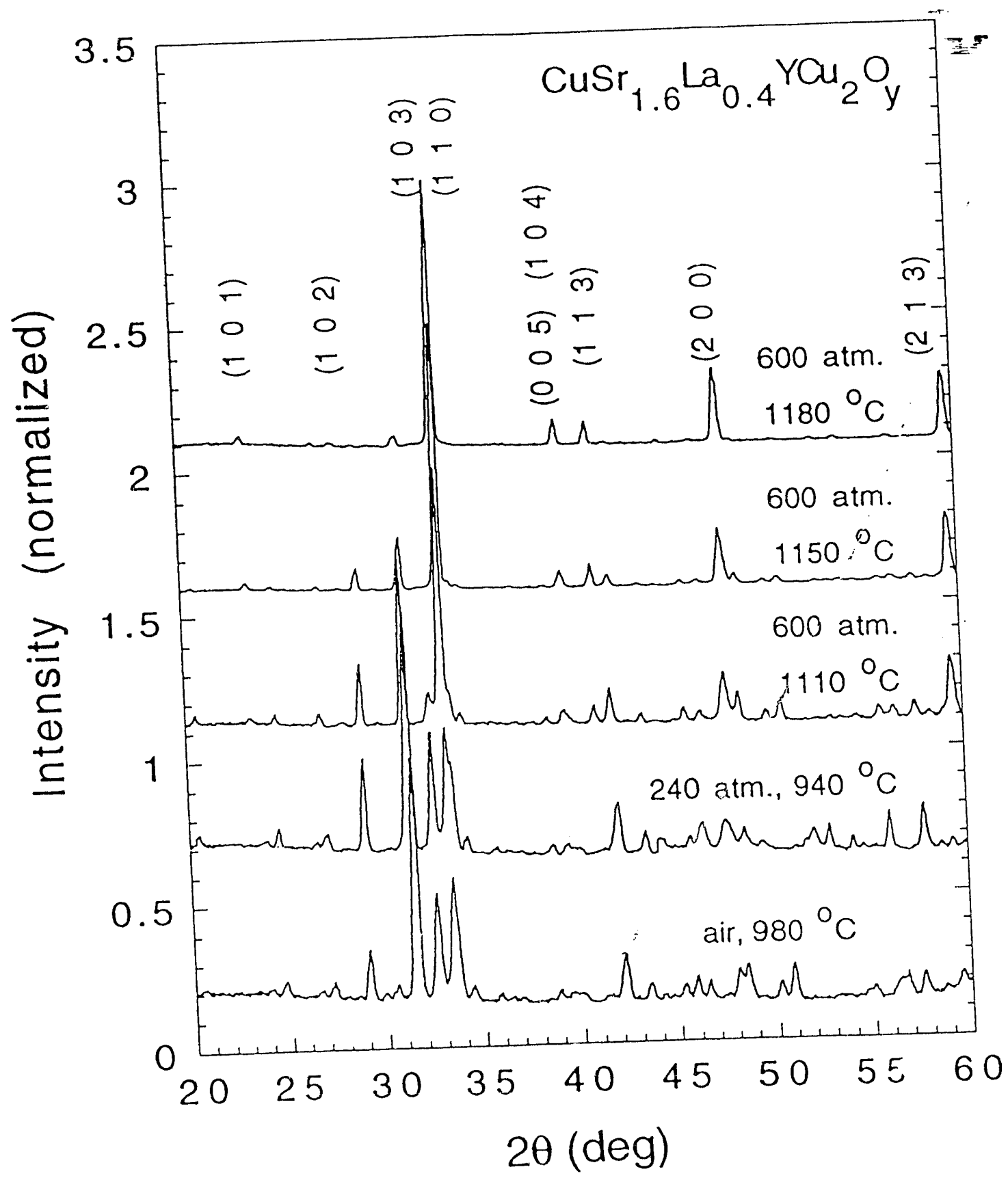

Fig. $2 X$-ray powder diffraction patterns for the $\mathrm{CuSr}_{1.6} \mathrm{La}_{0.4} \mathrm{YCu}_{2} \mathrm{O}_{7+\delta}$ sample synthesized at several oxygen pressures and temperatures. 

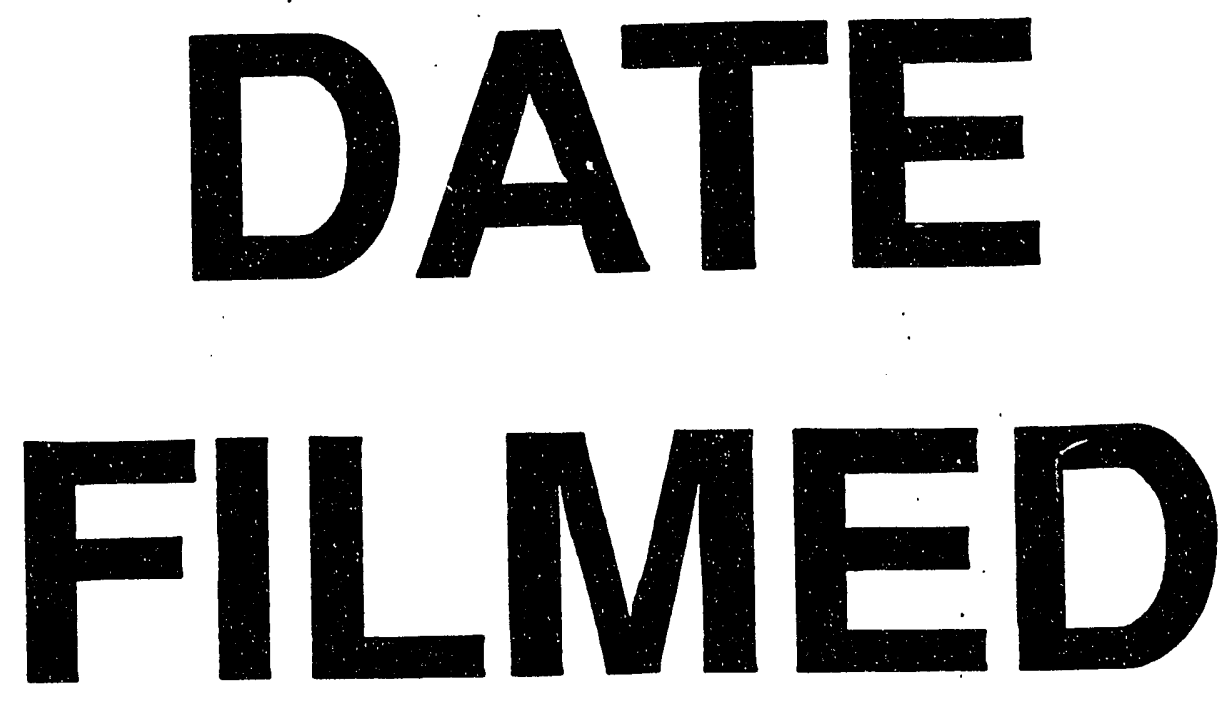

$11 / 19 / 93$
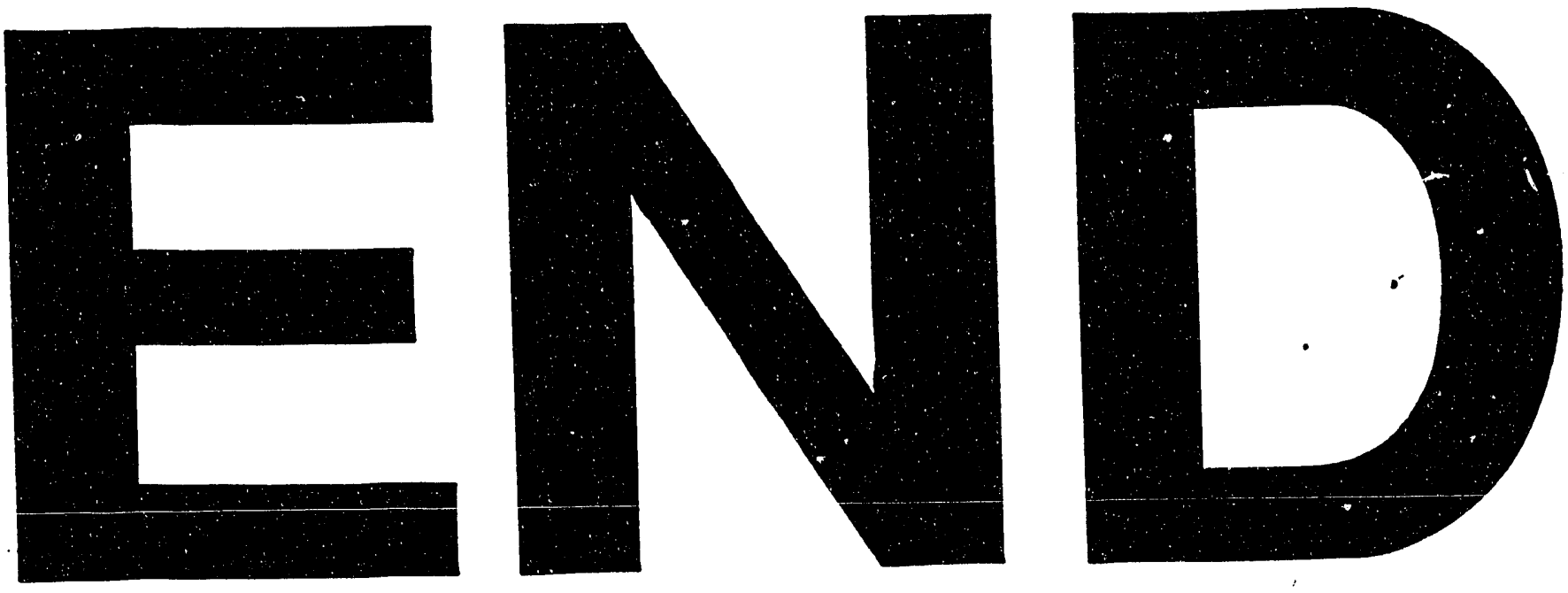